\title{
Frequency of Dental Caries and Level of Risk among Type II Diabetics
} Maria Moin* and Aeeza Malik

Department of Community Dentistry, DIKIOHS, Dow University of Health Sciences, Karachi, Pakistan

\begin{abstract}
Objective: To identify the dental caries status and evaluate its risk among patients with type II diabetes mellitus (Type II DM).
\end{abstract}

Methodology: A cross sectional study was carried out among 100 patients with type II DM, selected through consecutive sampling technique from Jinnah Post Graduate Medical Centre Department of Endocrinology, Karachi. The data was collected from 30-70 years old type II DM patients during the month of September 2013. After taking the consent, the dental caries status was recorded by using Decayed, Missed, Filled, Teeth (DMFT) index and the level of caries risk by Caries Assessment Management by Risk Assessment (CAMBRA) form. Oral examination was performed by a single trained examiner under daytime light using dental mirror and ball ended probe on mobile dental units.

Results: The mean DMFT score was found to be $4.9\left(D^{\top}=2, M^{\top}=2\right.$, and $\left.F^{\top}=0.09\right)$. The subjects at low risk were $11 \%$ whereas, $89 \%$ were at high level of risk for dental caries development. The mean duration of diabetes was 8.13 years and patients taking insulin were $28.3 \%$, whereas, $54.7 \%$ were taking hypoglycemic tablets and $17 \%$ were taking both.

Conclusion: Within the limits of the present study, the results indicated that patients with type II DM have high rate of dental caries and at high risk of caries development.

Keywords: Caries; Type II diabetes; Caries index; Risk assessment

\section{Introduction}

Majority of the systemic diseases evidently present oral symptoms and Diabetes Mellitus (DM) is not an exception. Persons with diabetes are at an increased risk of developing oral conditions such as gingivitis, periodontal disease, and alveolar bone loss, which has been associated with persistent poor glycemic control [1]. According to World Health Organization (WHO), DM has been increasing worldwide so abruptly that it is declared as an epidemic [2]. The prevalence of diabetes for all age groups worldwide was estimated to be $2.8 \%$ in 2000 and may reach $4.4 \%$ by 2030 . Additionally, the diabetic population is expected to rise from 171 million in 2000 to 3,666 million by 2030 [2]. DM is a group of metabolic diseases characterized by hyperglycemia resulting from defects in insulin secretion, insulin action, or both [3]. Roglic et al. reported that the almost 3 million deaths per year are attributed to diabetes, equivalent to $5.2 \%$ of all deaths [4,5]. Type II DM mostly occurs after 30 years of age and rarely occurs in kids and teenagers. It is also characterized by increased blood glucose level and obesity [6].

In terms of oral consequences, physical and biological risk factors for enamel or root caries include inadequate salivary flow and composition, high numbers of cariogenic bacteria, insufficient fluoride exposure, gingival recession, immunological components, need for special health care, and genetic factors. Caries are related to one's lifestyle and behavioral factors under a person's control are clearly implicated. These factors include poor oral hygiene, poor dietary habit such as frequent consumption of refined carbohydrates, frequent use of oral medications that contain sugars $[7,8]$. Compared to healthy people, patients with DM are liable to have higher and more severe dental caries and periodontal disease [9]. In addition, people with diabetes also have poor oral hygiene encompass elevated rate of plaque, calculus, tooth decay, gingival swelling and deep periodontal pockets. They are also more prone to infections, including dental abscesses that result from progressive dental caries [10].

As a consequence of hyposalivation and elevated salivary glucose levels due to severe insulin deficiency, diabetic patients are at a high risk of developing dental caries [7,8]. Diabetic patients are mostly on non-cariogenic diet as they are limiting carbohydrates from their diet but the increased glucose level in blood and saliva is the major predisposing factor behind the process of dental caries [7]. Aside from calcium and phosphates that help remineralize tooth enamel, saliva also contains components that can directly attack cariogenic bacteria. The absence of copious saliva may result in minimizing buffer activity which promotes remineralization of tooth structures early in the caries process and resulting in substantial increase in the caries risk [11].

Epidemiological studies have reported that elevated levels of calcium, phosphate, and fluoride in plaque may slow down the process of caries development. Previous studies also suggest that dental caries are produced due to the presence organic acid in dental plaque. Effect of low $\mathrm{pH}$ also contributes to this fact because it causes the dissolution of minerals calcium, phosphate, and fluoride [12-14]. The other important predisposing factor for the development of dental caries in diabetic patients is the poor glycemic control which leads to the impaired functioning of salivary glands and ultimately resulting in dryness of mouth [15].

Carie protective factors are biologic or therapeutic measures that can be used to prevent or arrest pathologic challenges posed by caries risk factors. Best practices dictate that once the clinician has identified patient's caries risk (low, moderate, high or extreme), a therapeutic and/or preventive plan may be implemented. Previous literature has reported an increased frequency of dental caries attributing to the existence of poor metabolic control [16-19]. However the purported increased risk of dental caries in relation to certain factors such as poor oral hygiene, lack of blood glucose control, unhealthy diet pattern,

*Corresponding author: Maria Moin, BDS, MDS Trainee, Lecturer, Department Of Community Dentistry, DIKIOHS-Dow University of Health Sciences, Karachi 77440, Pakistan, Tel: 0092-345-311023; E-mail: dr.maria.moin@hotmail.com

Received July 31, 2015; Accepted August 31, 2015; Published September 10 2015

Citation: Moin M, Malik A (2015) Frequency of Dental Caries and Level of Risk among Type II Diabetics. Dentistry 5: 334. doi:10.4172/2161-1122.1000334

Copyright: ( 2015 Moin M, et al. This is an open-access article distributed under the terms of the Creative Commons Attribution License, which permits unrestricted use, distribution, and reproduction in any medium, provided the original author and source are credited. 
Citation: Moin M, Malik A (2015) Frequency of Dental Caries and Level of Risk among Type II Diabetics. Dentistry 5: 334.

deficient control of administered insulin dose, physical exercise and meal timings have never been assessed simultaneously. Therefore, this study was intended with the objectives to identify the dental caries status and level of caries risk among TYPE II DM patients through the employment of Caries Assessment Management by Risk Assessment i.e. CAMBRA [20].

\section{Methodology}

A cross sectional study was carried out among 100 type II DM patients aging between 30-70 years who visited Jinnah Post Graduate Medical Centre, Department Of Endocrinology, Karachi, during the month of September 2013. The patients were selected through consecutive sampling technique and permission was obtained from the Department Of Endocrinology prior to the beginning of the data collection.

The subjects were healthy individuals of middle socioeconomic class with at least 10 years of diagnosed diabetes. At the time of the study no patient was taking any medications or being treated for medical problems other than type II diabetes. All uncontrolled type II DM diabetic patients with blood glucose level greater than $(>120 \mathrm{mg} /$ dl) of both genders with at least 20 teeth, taking medication (insulin/ tablet) were included. Individuals with any other diseases such as physical/mental retardation and non-consenting were excluded from the study.

After taking consent, the data were gathered through Performa which included questions regarding demographic information, duration (years since diagnosis of DM), treatment receiving (either insulin regimen or oral hypoglycemic tablets), level of control of diabetes and laboratory finding such as RBS, FBS and HbAlc levels (Figure 1). This information was also cross checked with their medical reports. The level of caries risk was assessed using Caries Management by Risk Assessment (CAMBRA) [20]. CAMBRA is an evidenced based approach of assessing caries risk by evaluating risk factors and patient's disease indicators (Figure 2). On the basis of risk assessment form, the dental team is capable to segregate patients into categories of low, moderate, high or severe risk without difficulty and then build wellversed suggestions for serving all patients to prevent caries. Through

\section{ORAL HEALTH RECORD PERFORMA FOR DAIBETICS}

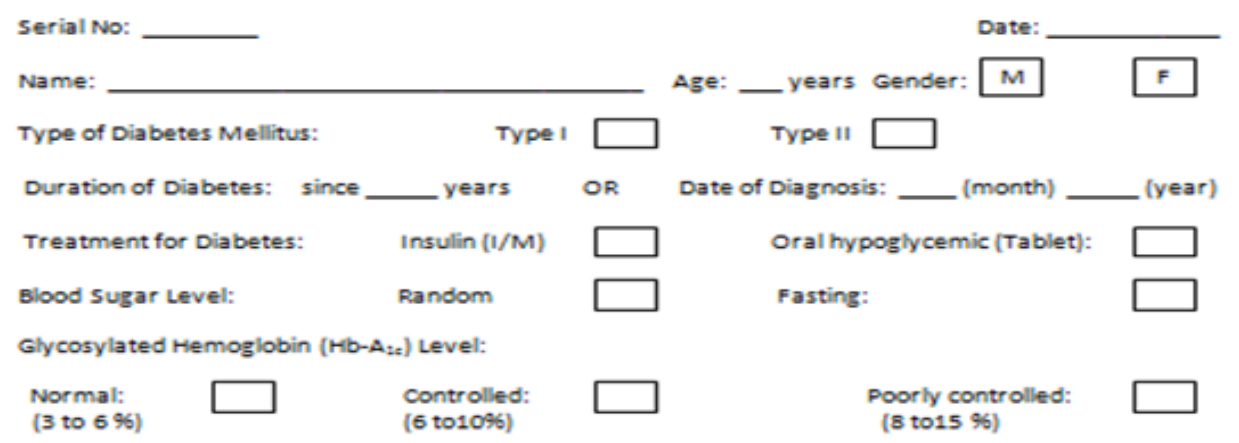

DENTAL CARIES STATUS:

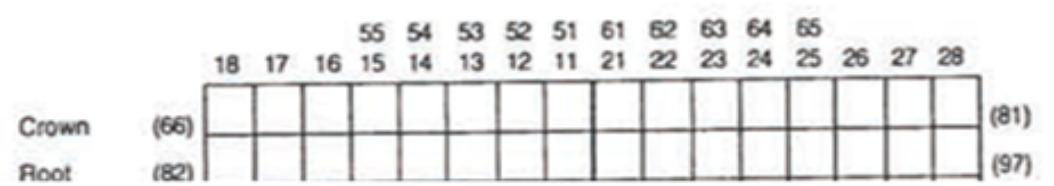

De Decayed $M=$ Missing F=Filled

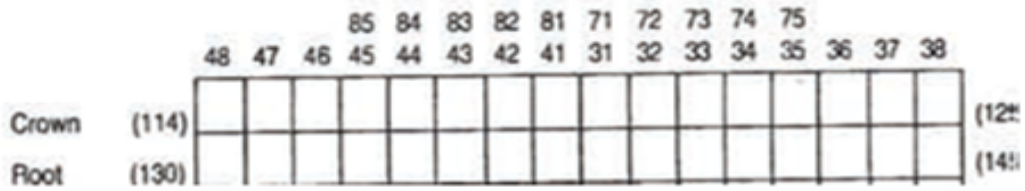

Figure 1: Oral Health Record Performa for Diabetics. 
Citation: Moin M, Malik A (2015) Frequency of Dental Caries and Level of Risk among Type II Diabetics. Dentistry 5: 334. doi:10.4172/2161-1122.1000334

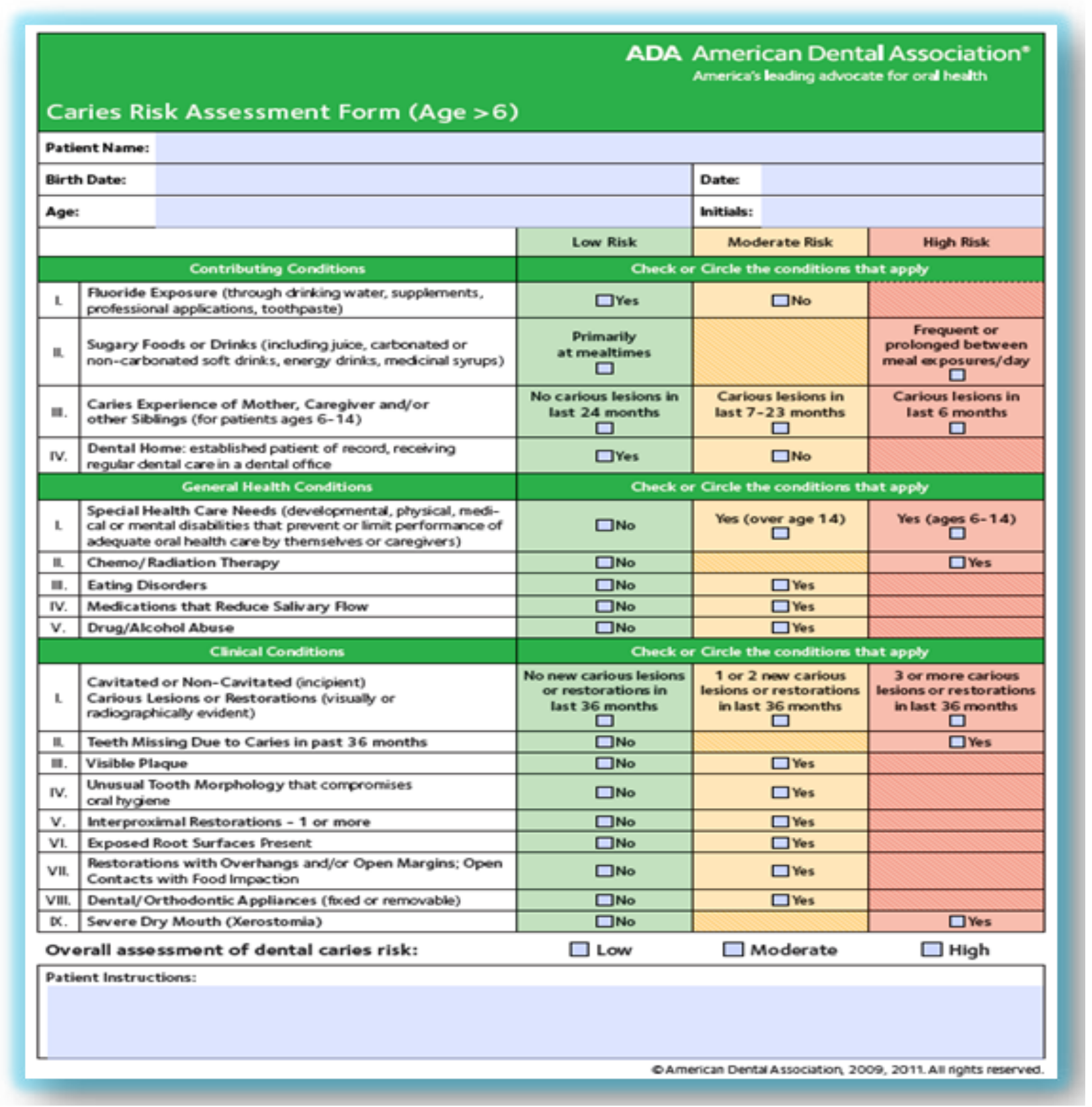

Figure 2: Caries Risk Assessment Form.

CAMBRA the information was collected regarding contributory, general health conditions and the clinical examination was performed to assess clinical conditions. The contributory conditions include information related to fluoride exposure, sugar intake and caries experience of mothers/ care givers. The presence of fluoride exposure was assessed by asking the utilization of fluoride supplements and fluoridated toothpaste. The sugar intake was assessed by juice, carbonated or non-carbonated soft drinks, energy drinks consumption. The general health conditions include special health care needs, medications that cause dryness of mouth and drug/ alcohol abuse. The clinical examination includes dry mouth, cavitated and non cavitated lesions, dental plaque, teeth missing due to caries, exposed root surfaces and restorations with over hangs margins. The collected information was assessed by cross questioning.
After completing the Performa, an examination was done under natural sunlight with proper sterilized instruments and disposal. The tool used to evaluate caries status was DMFT index. The patients were asked to sit on mobile dental unit with back straight and head rested in a supine position. The examination was done quadrant wise on all present teeth with gloves and mask, the surface was cleaned and dried by using cotton. The decayed, missed and filled scores of teeth were recorded by a single examiner using dental mirror and ball end probe and DMFT index was used to record the dental caries status [21]. Data was entered and analyzed using SPSS (Statistical Package for Social Sciences) version 16. Descriptive statistics were employed to obtain the mean DMFT (standard deviation) and the frequencies of the responses of CAMBRA form. 


\section{Results}

One hundred patients were examined out of which $10 \%$ were male and $90 \%$ were females with the mean age of $48 \pm 13$ years. The mean DMFT score was found to be $4.9\left(\mathrm{D}^{\mathrm{T}}=2, \mathrm{M}^{\mathrm{T}}=2\right.$, and $\left.\mathrm{F}^{\mathrm{T}}=0.09\right)$. The mean duration of diabetes was 8.13 years. Patients taking insulin were $28.3 \%$ while $54.7 \%$ were taking hypoglycemic tablets and $17 \%$ were taking both. Table 1 reveals the frequency of responses self-reported by the subjects employing CAMBRA form and co-existing clinical conditions as reported after dental examination. Same table identifies that the subjects at low risk were $11 \%$ whereas, $89 \%$ were at high level of risk for dental caries development.

\section{Discussion}

This study was planned to evaluate the dental caries status of type II DM patients and the level of caries risk among these subjects. CAMBRA form was used to assess caries risk by evaluating risk factors and patient's disease indicators. It was first introduced in 2003 when an unofficial group called the Western CAMBRA Coalition was formed that included stakeholders from education, research, industry, governmental agencies and private practitioners based in the western region of the United States. It has the background principle of preventing or treating the cause of dental caries at the earliest stages rather than waiting for irreversible damage to the teeth [2].

In the present study the mean DMFT score of diabetic patients was found to be 4.9, higher than reported by World Health Organization (WHO) [18]. The CAMBRA form has identified that around $90 \%$ of the diabetic participants were at high risk of developing dental caries.
Low fluoride exposure, increase frequency of taking sugary food and soft drinks and observed xerostomia were the prominent reasons being reported behind this increased risk for caries.

Present data reported poor oral health knowledge, attitude and practices among the selected population as excessive plaque, poor restoration status (overhangs) and exposed root surfaces were identified in majority of the participants. Also $41 \%$ of the participants self-reported the development of 3 or more carious lesions in last 36 months, which demonstrate poor oral hygiene maintenance and low practices of preventive strategies by this particular group in observation. This also suggest that decreased salivary flow and increased concentration of glucose in blood and saliva favored the growth of oral bacteria, resulting in high prevalence of caries in the diabetic patients in spite of low cariogenic potential of diet. Previous literature evidently suggests that past caries experience is the single best predictor for future caries development [15]. Earlier epidemiological study has reported low prevalence of dental caries in diabetics as compared nondiabetics. Findings of the present study are in line with the study of Malicka et al. which reported high mean DMFT in type II diabetics as compared with type I diabetic patients and healthy individuals [7]. Another study conducted in Pakistan in 2011 identified a mean DMFT of 2.49 in diabetic patients in contrast to 0.53 in control group [22]. Current study is also in line with a previous study conducted in 2011 as it has revealed cases with exposed root surfaces which may predict the increased susceptibility to root caries in type II DM patients probably due to the increased incidence of gum recession, the development of root caries may increase [7].

\begin{tabular}{|c|c|c|}
\hline Contributing Oral Conditions & Response Yes/No & Response (\%) \\
\hline Fluoride exposure (through drinking water, supplements, professional applications, toothpaste) & $\begin{array}{l}\text { Yes } \\
\text { No }\end{array}$ & $\begin{array}{l}27 \% \\
73 \%\end{array}$ \\
\hline $\begin{array}{l}\text { Sugary food or drinks (including juices, carbonated or non- carbonated soft drinks, energy drinks, } \\
\text { medicinal syrups) }\end{array}$ & $\begin{array}{l}\text { - Primarily at meal times } \\
\text { - Frequently between meal exposures/day } \\
\text { - Prolonged between meal exposures/day }\end{array}$ & $\begin{array}{l}27 \% \\
63 \% \\
10 \%\end{array}$ \\
\hline Dental Home: established patient of record, receiving regular dental care in a dental office & $\begin{array}{l}\text { Yes } \\
\text { No }\end{array}$ & $\begin{array}{l}66 \% \\
34 \%\end{array}$ \\
\hline \multicolumn{3}{|l|}{ General Health Conditions } \\
\hline $\begin{array}{l}\text { Special health care needs (developmental, physical, medical or medical disabilities that prevent or limit } \\
\text { performance of adequate oral health care by themselves or care givers) }\end{array}$ & $\begin{array}{l}\text { No } \\
\text { Physical } \\
\text { Medical }\end{array}$ & $\begin{array}{l}26 \% \\
68 \% \\
6 \%\end{array}$ \\
\hline Eating Disorders & $\begin{array}{l}\text { No } \\
\text { Constipation } \\
\text { Nausea } \\
\text { All }\end{array}$ & $\begin{array}{c}45 \% \\
47 \% \\
4 \% \\
4 \%\end{array}$ \\
\hline Drug/Alcohol abuse & $\begin{array}{l}\text { Yes } \\
\text { No }\end{array}$ & $\begin{array}{l}27 \% \\
37 \%\end{array}$ \\
\hline \multicolumn{3}{|l|}{ Clinical Conditions } \\
\hline $\begin{array}{l}\text { Cavitated or Non-Cavitated (incipient) } \\
\text { Carious Lesions or Restorations (visually or radiographically evident) }\end{array}$ & $\begin{array}{l}\text { - } \quad \text { No new carious lesions or restorations past } \\
3 \text { months } \\
\text { - } 1 \text { or } 2 \text { new carious lesions last } 36 \text { months } \\
\text { - } 3 \text { or more carious lesions last } 36 \text { months }\end{array}$ & $\begin{array}{l}26 \% \\
31 \% \\
41 \%\end{array}$ \\
\hline Plaque & $\begin{array}{l}\text { Yes } \\
\text { No }\end{array}$ & $\begin{array}{l}50 \% \\
50 \%\end{array}$ \\
\hline Exposed Root Surfaces & $\begin{array}{l}\text { Yes } \\
\text { No }\end{array}$ & $\begin{array}{l}56 \% \\
44 \%\end{array}$ \\
\hline Restorations with overhang margins & $\begin{array}{l}\text { Yes } \\
\text { No }\end{array}$ & $\begin{array}{l}98 \% \\
2 \%\end{array}$ \\
\hline Dental Orthodontic Appliances & $\begin{array}{l}\text { Yes } \\
\text { No }\end{array}$ & $\begin{array}{c}8 \% \\
92 \%\end{array}$ \\
\hline Sever Dry Mouth ( Xerostomia ) & $\begin{array}{l}\text { Yes } \\
\text { No }\end{array}$ & $\begin{array}{l}50 \% \\
50 \%\end{array}$ \\
\hline Level of Risk & $\begin{array}{l}\text { Low } \\
\text { High }\end{array}$ & $\begin{array}{l}11 \% \\
89 \%\end{array}$ \\
\hline
\end{tabular}

Table 1: Self-reported responses to CAMBRA Form and coexisting clinical conditions. 
Citation: Moin M, Malik A (2015) Frequency of Dental Caries and Level of Risk among Type II Diabetics. Dentistry 5: 334. doi:10.4172/2161-1122.1000334

Page 5 of 5

Moore et al. reported an increased prevalence of caries in type I diabetics, located particularly in the root or cervical regions. The authors related this observation to the age of the patients, the presence of increased gingival recession, and the presence of concomitant kidney disease. Caries of this kind have also been related to a specific diet based on carbohydrates, with an incorrect provision of calcium and phosphorus. However, this is in contrast to the fact that patients with good diabetes control have reduced sugar intakes [23].

Present study may present the limitation that this was an institutional based study and therefore the results may not be generalized. This suggests a clear requirement of larger scale, community level research in this field. Also apart from CAMBRA form and DMFT recording, other standard dental indices such as oral hygiene index, plaque index, gingival index, bleeding index and clinical attachment loss may also be employed to report the simultaneous periodontal status in type II diabetic patients. Oral microbial counts, quantity and flow rate of saliva, oral hygiene data, and total number of root surfaces with caries and fillings which may be useful in this study were not available.

\section{Conclusion}

Within the limits of the present study, the results indicated that type II DM patients were at high risk of caries development. This recommends that the anticipation of dental caries may be based on caries risk assessment in order to prevent and control the burden of dental caries infection in this particular group.

\section{References}

1. Grossi SG (2001) Treatment of periodontal disease and control of diabetes: an assessment of the evidence and need for future research. Ann Periodontol 6: $138-45$.

2. Smyth S, Heron A (2006) Diabetes and obesity: the twin epidemics. Nat Medicine 12: $75-80$

3. American Diabetes Association (2004) Diagnosis and Classification of Diabetes Mellitus. Diabetes Care 27: S5-S10.

4. Aziz HK (2012) The relationship between the dental caries and the blood glucose level among type II non insulin dependent diabetic patients. J Bagh College Dentistry 24: 108-114.

5. Vaziri PB, Vahedi M, Abdollahzadeh SH, Abdolsamadi HR, Hajilooi M, et al. (2009) evaluation of salivary albumin in diabetic patients. Iranian J Public Health 38: 54-59.

6. Alemzadeh R, Wyatt DT (2004) Diabetes mellitus. In: Nelson Textbook of Pediatrics. (1 $7^{\text {th }}$ edn), Saunders, Philadelphia.
7. Malicka B, Kaczmarek U, Ziętek M (2011) Dental caries in adult patients with type 1 and 2 diabetes mellitus. J Stoma 64: 9-24.

8. Selwitz RH, Ismail AI, Pitts NB (2007) Dental caries. Lancet 369: 51-59.

9. Fejerskov O, Kidd EAM (2003) In: Dental caries: the disease and its clinical management. Blackwell Munksgaard, Copenhagen.

10. Hintao J, Teanpaisan R, Chongsuvivatwong V, Ratarasan C, Dahlen G (2007) The microbiological profiles of saliva, supragingival and subgingival plaque and dental caries in adults with and without type 2 diabetes mellitus. Oral Microbiol Immunol 22:175-181.

11. Yeh CK, Harris SE, Mohan S, Horn D, Fajardo R (2012) Hyperglycemia and xerostomia are key determinants of tooth decay in type 1 diabetic mice. Lab Invest 92: 868-882.

12. Ship JA (2003) Diabetes and oral health: an overview. J Am Dent Assoc 134 :4S-10S.

13. Moore PA, Orchard T, Guggenheimer J, Weyant RJ (2000) Diabetes and ora health promotion: a survey of disease prevention behaviours. J Am Dent Assoc 114: 1333-1341.

14. Eldarrat $\mathrm{AH}$ (2011) Awareness and attitude of diabetic patients towards their increased risk for oral diseases. Oral Health Prev Dent 9: 235-241.

15. Bots CP, Brand HS, Veerman EC, van Amerongen BM, Nieuw Amerongen AV (2004) Preferences and saliva stimulation of eight different chewing gums. Int Dent J 54: 143-148.

16. Selwitz RH, Ismail AI, Pitts NB (2007) Dental caries. Lancet 369: 51-59.

17. Syrjälä AM, Ylöstalo P, Niskanen MC, Knuuttila ML (2004) Relation of different measures of psychological characteristics to oral health habits, diabetes adherence and related clinical variables among diabetics. Eur J Oral Sci 112:109-114.

18. Siudikiene J, Maciulskiene V, Dobrovolskiene R, Nedzelskiene I (2005) Oral hygiene in children with type I diabetes mellitus. Stomatologija 7: 24-27.

19. Siudikiene J, Maciulskiene V, Nedzelskiene I (2005) Dietary and oral hygiene habits in children with type I diabetes mellitus related to dental caries. Stomatologija 7: 58-62.

20. Young DA, Buchanan PM, Lubman RG, Badway NN (2007) New directions in interorganizational collaboration in dentistry; the CAMBRA Coalition model. J Dent Educ 71: 595-600.

21. World Health Organization (1997) Oral health surveys- basic methods. (4 edn), WHO, Geneva.

22. Iqbal S, Kazmi F, Asad S, Mumtaz M, Khan AA (2011) Dental caries \& diabetes mellitus. Pak Oral Dental J 31: 60-63.

23. Miralles L, Silvestre FJ, Hernández-Mijares A, Bautista D, Llambes F, et al (2006) Dental caries in type 1 diabetics: influence of systemic factors of the disease upon the development of dental caries. Med Oral Patol Oral Cir Bucal 11: $256-260$. 